\title{
The Value of Clinical Teachers for EMR Implementations and Conver- sions
}

L.A. Stevens ${ }^{1,2}$; J.L. Pantaleoni ${ }^{1,2}$; C.A. Longhurst ${ }^{1,2}$

${ }^{1}$ Department of Pediatrics, Stanford University School of Medicine, Stanford, California;

2Department of Clinical Informatics, Stanford Children's Health, Palo Alto, California

\section{Keywords}

Physicians, electronic medical record, EMR, education

\section{Summary}

Effective physician training is an essential aspect of EMR implementation. However, it can be challenging to find instructors who can present the material in a clinically relevant manner. The authors describe a unique physician-training program, utilizing medical students as course instructors. This approach resulted in high learner satisfaction rates and provided significant cost-savings compared to alternative options.

\section{Correspondence to:}

Lindsay A. Stevens, MD, FAAP

Clinical Instructor of Pediatrics, Stanford University

School of Medicine

Physician Lead for Ambulatory Training - Clinical In-

formatics, Stanford Children's Health

Email: lindsay.stevens@stanford.edu
Appl Clin Inform 2015; 6: 75-79

http://dx.doi.org/10.4338/ACl-2014-09-IE-0075

received: September 27, 2014

accepted: November 7, 2014

published: February 11, 2015

Citation: Stevens LA, Pantaleoni JL, Longhurst CA. The value of clinical teachers for EMR implementations and conversions. Appl Clin Inf 2015; 6: 75-79

http://dx.doi.org/10.4338/ACI-2014-09-IE-0075 
At Stanford Children's Health, we recently underwent a large-scale electronic medical record (EMR) transition from one commercially available system to another. As reflected in the literature, effective end-user training is an essential aspect of implementing an EMR, but often institutionally underinvested [1-6].

It can be particularly challenging to find course instructors who can not only impart needed information in a captivating way, but can also contextualize how the providers will use the system. Other institutions have found that providers favor having physician champions in the classroom, however there is little published data on the use of instructors with clinical backgrounds $[7,8]$. It makes logical sense that the instructors who would be best at imparting knowledge in a relevant manner would be peer clinicians. At Stanford, we aimed to have our providers trained through clinical scenarios that modeled workflows in the hospital and clinic settings, and thus aspired to have our EMR training courses taught by clinicians [9].

Barriers to having instructors who are physicians are the cost and the time that they would need to donate to the endeavor. With over 1000 providers to train in a 2-month window of time, it was not feasible to pull attending physicians from their scheduled duties. Given that we are an academic institution, trainees are actively involved in patient care, and serendipitous timing allowed medical students to be included in the training team.

We selected 6 fourth-year medical students to participate as paid credentialed trainers (CTs) for our physician classroom training. During the interview for the CT position, applicants were asked to teach on a topic of their choosing, utilizing any tools at their disposal. They were also asked questions which spoke to their flexibility, communication skills, and ability to work in a team. Once selected, the trainers completed a 6-week course, which included instruction on adult learning theory [10], change management [11], and conflict resolution [12]. The course also included ample time for content understanding and development. As an assessment, the CTs were required to do a "teachback" with the instructional designer, as well as with their peers. In order to obtain their "credentialed" status, they also had written and oral examinations with the EMR vendor and institutional training leaders. Uniquely, given the medical students' clinical experience, they were also able to work with the instructional designers to improve course content and frame the training to suit provider needs.

We recruited the medical students in the Fall prior to the May 2014 go-live, in order to help them plan the completion of their medical school training. Their training as CTs began at the end of January 2014, with the first 4 weeks dedicated to skill building and course content familiarity and the final two weeks dedicated practice teaching and training classroom support super users. End-user training began in March 2014 and proceeded through the end of April 2014.

Externally contracted credentialed trainers can cost up to $\$ 150$ per hour including expenses. By hiring internal CTs, we were able to save on overhead while still offering the students a higher pay rate than they would earn at virtually any other student job. We estimate a cost reduction of approximately 50\% for the medical student CTs hired internally - with a project savings of over $\$ 200,000$ during the course of training. We surveyed our medical students following completion of their experience on the project, and all listed finances as their number one reason for applying. Other incentives to these medical students included acquisition of teaching skills and career opportunities.

We anticipated that the medical students would be successful, but were astounded by the feedback we received. Medical student trainers were given extremely high marks on our post-training survey, averaging 3.93 on a 4-point Likert scale for both mastery of material and communication skills ( 4 being excellent, 1 being poor), with minimal standard deviation ( Table 1 ). Comment themes from these evaluations were also consistently positive, for example: "Trainers were great they were clear, knew the system well and were extremely patient," "Engaging and interactive instruction," "Instructors did an excellent job."

In our survey of the student CTs, all of them reported having a positive experience. The medical students reported feeling much more competent in their teaching abilities, in conflict resolution, and in their abilities to use an EMR following the project. A few even called it "the highlight of medical school" and developed an interest in pursuing a career in medical informatics. In addition, student CTs felt that they were well received by the faculty members and other providers taking the course. One medical student commented: "I think there was a definite difference in how we were treated by providers compared to other educators. I felt like they were more engaged and perhaps willing to be 
more honest about their concerns and fears in our classrooms. For the most part, I felt I was well respected and appreciated by the providers. My impression was that the providers felt positively about being trained by a medical student."

Overall, using trainers who can provide a clinical context, and who have direct clinical experiences to add to the EMR curriculum, is extremely beneficial. These individuals can relate to the provider on a different level than those without such experiences. Using medical students can help achieve this in a cost-effective way while providing them with a valuable financial and career opportunity.

\section{Conflicts of Interest}

The authors have no conflicts of interest to report.

\section{Human Subjects Protection}

The Stanford University School of Medicine Institutional Review Board (IRB) determined this project to be exempt from further review as this activity did not meet the definition of research.

\section{Acknowledgements}

The authors would like to acknowledge Leon Castaneda, MD, Kevin Chi, MD, Alison Chiang, MD, Deborah Fretwell, MD, Daniel Gessner, MD, and Arpeet Shah, MD for their excellent help with our training process. We would also like to thank Warren Chandler, Bethany Goad, RN, MSN, and Vickey Weir, BSN, MPA for their leadership and coordination of our training efforts. 
Table 1 Post-training survey responses for Medical Student Trainers

\begin{tabular}{|l|c|c|c|c|c|l|l|}
\hline Question & Excellent & Good & Fair & Poor & $\begin{array}{l}\text { Total } \\
\text { Answers }\end{array}$ & $\begin{array}{l}\text { Mean } \\
\text { Score }\end{array}$ & Std Dev \\
\hline Instructor's mastery of subject & 554 & 43 & 0 & 0 & 597 & 3.9279 & 0.2585 \\
\hline Instructor's communication skills & 556 & 44 & 0 & 0 & 600 & 3.9266 & 0.2606 \\
\hline
\end{tabular}




\section{References}

1. Brokel JM, Harrison MI. Redesigning care processes using an electronic health record: a system's experience. Joint Commission journal on quality and patient safety / Joint Commission Resources 2009; 35(2): $82-92$.

2. Lorenzi NM, Kouroubali A, Detmer DE, Bloomrosen M. How to successfully select and implement electronic health records (EHR) in small ambulatory practice settings. BMC medical informatics and decision making 2009; 9: 15.

3. McAlearney AS, Robbins J, Hirsch A, Jorina M, Harrop JP. Perceived efficiency impacts following electronic health record implementation: an exploratory study of an urban community health center network. Int J Med Inform 2010; 79(12): 807-816.

4. Terry AL, Thorpe CF, Giles G, Brown JB, Harris SB, Reid GJ, Thind A, Stewart M. Implementing electronic health records: Key factors in primary care. Canadian family physician Medecin de famille canadien 2008; 54(5): 730-736.

5. Whittaker AA, Aufdenkamp M, Tinley S. Barriers and facilitators to electronic documentation in a rural hospital. Journal of nursing scholarship : an official publication of Sigma Theta Tau International Honor Society of Nursing / Sigma Theta Tau 2009; 41(3): 293-300.

6. Ajami S, Bagheri-Tadi T. Barriers for Adopting Electronic Health Records (EHRs) by Physicians. Acta informatica medica: AIM: journal of the Society for Medical Informatics of Bosnia \& Herzegovina: casopis Drustva za medicinsku informatiku BiH 2013; 21(2): 129-134.

7. Abramson EL, Patel V, Malhotra S, Pfoh ER, Nena Osorio S, Cheriff A, Cole CL, Bunce A, Ash J, Kaushal R. Physician experiences transitioning between an older versus newer electronic health record for electronic prescribing. Int J Med Inform 2012; 81(8): 539-548.

8. Kushinka SA. Training strategies: EHR deployment techniques. California Healthcare Foundation 2010; Issue Brief.

9. Pantaleoni JP, et al. Successful physician training program for large scale EMR Implementation. Applied Clinical Informatics 2014; 6: 80-95.

10. Silver HF, Strong RW, Perini MJ. So each may learn: Integrating learning styles and multiple intelligences. Alexandria, VA: Association for Supervision and Curriculum Development; 2000.

11. Adams M. Change Your Questions, Change Your Life: 10 Powerful Tools for Life and Work. 2nd ed. San Francisco, CA: Berrett-Koehler Publishers; 2009. 240 p.

12. Kilmann RH, Thomas KW. Developing a forced-choice measure of conflict-handling behavior: the "Mode" instrument. Educ Psychol Meas. 1977;'37(2): 309-325. 